\title{
Amazônia: explorando o baixo Rio Branco - Roraima/Amazonas
}

\section{Amazon: exploring the low Rio Branco - Roraima /Amazonas}

\author{
Maria Madalena Aguiar Cavalcante ${ }^{* 1} \bowtie$ (D) , Antonio Tolrino de Rezende Veras $2 ₫$ (ID), \\ Giovanni de Farias Seabra $3 \bowtie(D$, Josué da Costa Silva $1 \bowtie(\mathbb{D})$, Maria das Graças \\ Nascimento Silva $1 \bowtie(0)$, Wagner Costa Ribeiro $4 \square$ (D)
}

\author{
${ }^{1}$ Departamento de Geografia, Universidade Federal de Rondônia, Porto Velho, Rondônia, Brasil \\ 2 Instituto de Geociências, Universidade Federal de Roraima, Boa Vista, Roraima, Brasil \\ ${ }^{3}$ Departamento de Geografia, Universidade Federal da Paraíba, João Pessoa, Paraíba, Brasil \\ 4Departamento de Geografia, Faculdade de Filosofia, Letras e Ciências Humanas, Universidade \\ de São Paulo, São Paulo, São Paulo, Brasil \\ Emails: antonio.veras@ufrr.br (ATRV); gioseabra@gmail.com (GFS); jcosta1709@gmail.com \\ (JCS); gracinhageo@hotmail.com (MGNS); wribeiro@usp.br (WCR) \\ E-mail para correspondência: mada.geoplan@gmail.com
}

Recebido (Received): 08/06/2020 Aceito (Accepted):01/12/2020

\begin{abstract}
Resumo: Esse artigo retoma uma importante tradição da Geografia brasileira: os relatos de campo. Ele apresenta a visão de pesquisadores que, durante 10 dias de maio de 2019, percorreram o rio Branco para visitar 16 comunidades em Roraima. Ao longo do período foram utilizadas diferentes técnicas de pesquisa, como a coleta de depoimentos de membros das comunidades por meio de entrevistas informais, rodas de conversa com lideranças, o registro fotográfico e em vídeo, assim como anotações de observações em campo. Também foram realizadas análises a bordo entre os membros da equipe que culminaram na produção desse artigo. O objetivo da pesquisa é conhecer e identificar potenciais, carências e vivências de comunidades que vivem à beira de rios em Roraima. $\mathrm{O}$ relato constatou que as comunidades estão sujeitas a lógicas externas, como o turismo internacional, que afeta drasticamente o modo de vida, bem como dependem de centros urbanos, como Boa Vista e Manaus, para escoar sua produção, baseada no extrativismo. Ainda assim, observou-se que as comunidades conseguem expressar o bem viver, posto que não desejam abandonar os lugares onde vivem. Por fim, verificou-se também que o cotidiano das mulheres é diferente dos homens, seja na participação da produção de farinha ou na pesca, seja no lazer.
\end{abstract}

Palavras-chave: Bem viver; Populações tradicionais; Unidade de conservação; Trabalho de campo.

Abstract: This article takes up an important tradition of Brazilian Geography: field reports. It presents the vision of researchers who, during 10 days of May 2019, traveled the Rio Branco to visit 16 communities in Roraima. Throughout the period, different research techniques were used, such as the collection of testimonies from members of the communities through informal interviews, conversation circles with leaders, the photographic and video recordings, as well as notes from field observations. On-board analyzes were also carried out among the team members that culminated in the production of this article. The objective of the research is to know and identify potentials, needs and experiences of communities that live by the rivers in Roraima. The report found that communities are subject to external logic, such as international tourism, which drastically affects the way of life, as well as depending on urban centers, such as Boa Vista and Manaus, to drain their production, based on extraction. Even so, it was observed that communities are able to express good living, since they do not want to leave the places where they live. Finally, it was also found that the daily lives of women are different from men, whether in the participation of flour production or in fishing, or in leisure.

Keywords: Well live; Traditional populations; Conservation unit; Fieldwork. 


\section{Introdução}

A região do Baixo rio Branco é o que podemos chamar um lugar distante. Explicando, distante quando nos referimos às distâncias reais, em quilômetros, e, longínquos, ao considerarmos os percursos que demandam horas e dias ao sabor das vias fluviais, principais artérias de transporte e comunicação entre as comunidades, povoados, vilas e cidades amazônicas.

O relato em tela é fruto das observações, experiências adquiridas e reflexões no transcurso do Projeto Baixo rio Branco: potencialidades e vivências, sediado na Universidade Federal de Roraima. Como parte do projeto, foi realizada a segunda expedição exploratória, com o objetivo de conhecer e vivenciar experiências de comunidades na porção sul do estado de Roraima.

A primeira viagem do Projeto Baixo rio Branco ocorreu em outubro de 2018, quando sete pesquisadores, a bordo de dois barcos pequenos navegaram durante 11 dias, por $1100 \mathrm{~km}$ de rios, lagos e igarapés. O trabalho revelou, inicialmente, que as comunidades dependem umas das outras e de centros regionais, mesorregionais e microrregionais, de Boa Vista, Caracaraí e Santa Maria do Boiaçu (Roraima); Manaus, Barcelos, Novo Airão e Moura (Amazonas). Esse quadro reflete a situação urbana na Amazônia brasileira, que foi estudada por Egler (2006), Trindade e Tavares (2008), Becker (2013), Batista e Ribeiro (2014), Schor (2015), Nunes et. al. (2016), Trindade e Madeira (2016), entre outros.

O Baixo rio Branco está localizado nas fronteiras meridionais do estado de Roraima com o noroeste do estado do Amazonas. A intrincada rede hídrica tecida com rios, igarapés, furos e paranás, esconde quase duas dezenas de povoados ribeirinhos. Aqui e acolá alguns lugarejos estão desabitados. É o fenômeno do "comunicídio", ou seja, são comunidades que desapareceram em razão das emigrações dos caboclos, das caboclas e dos "curumins" que jaziam em total abandono social, econômico e existencial. No coração da Hiléia Brasileira, os chamados "povos da floresta", as esquecidas comunidades ribeirinhas, formadas de índios, caboclos, foragidos e aventureiros resistem. Cada qual com suas peculiaridades originárias e amazônicas.

Durante dez dias do mês de maio de 2019, realizamos um trabalho de campo ao longo do Baixo rio Branco, no estado de Roraima, onde foi possível visitar dezesseis comunidades vinculadas politicamente aos municípios de Rorainópolis e Caracaraí (Figura 1). As comunidades que estão localizadas na margem direita do rio, pertencem ao Município de Caracaraí e aquelas situadas na margem esquerda pertencem ao Município de Rorainópolis. Parte da área percorrida está integrada à Área de Proteção Ambiental Baixo rio Branco (APABRB), criada pela Lei $n^{\circ} 555$ de 14 de julho de 2006, que no momento está em transição para se tornar uma Reserva de Desenvolvimento Sustentável, a partir de reivindicações das comunidades.

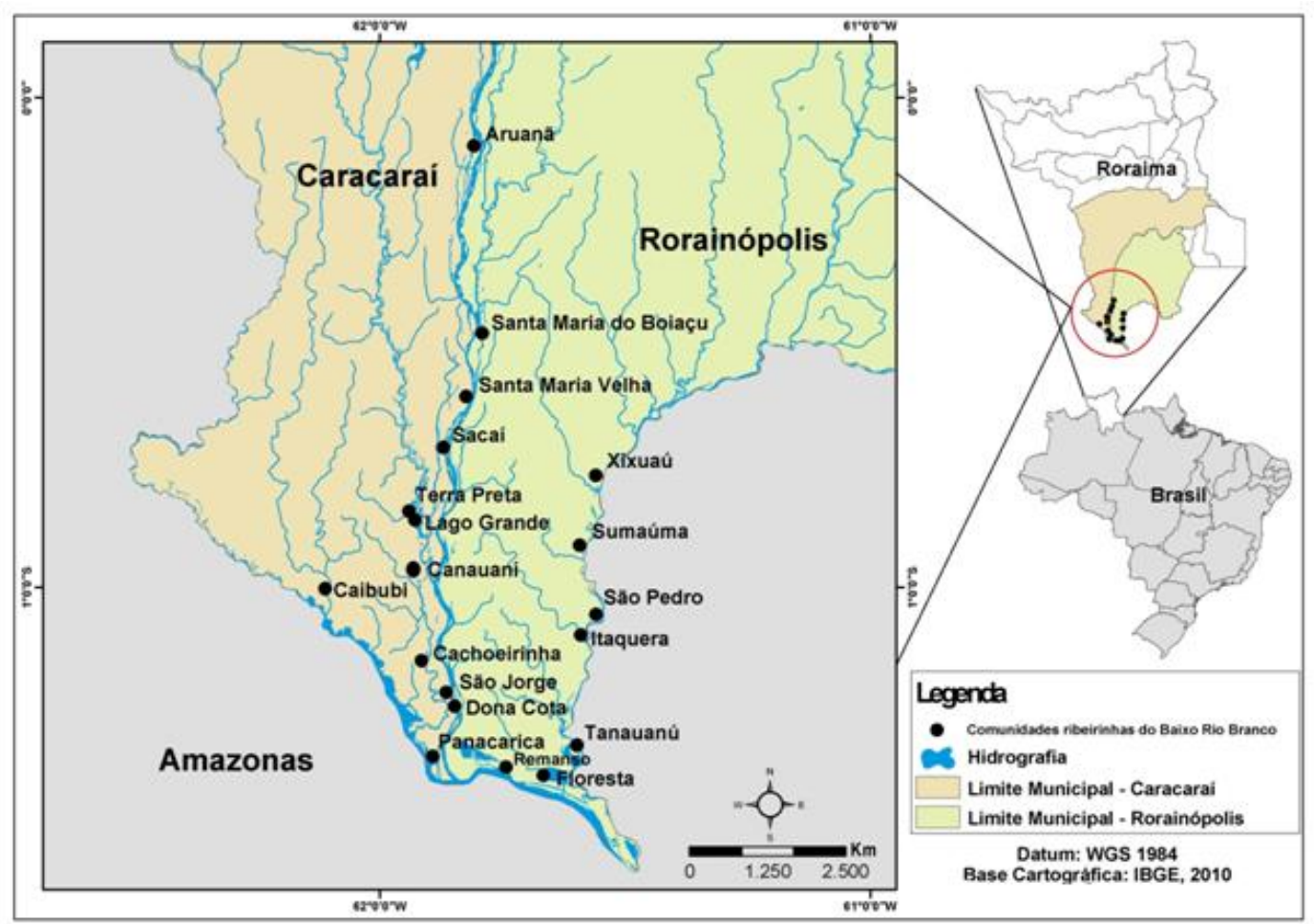

Figura 1: Mapa de localização das Comunidades visitadas. Fonte: Secretaria de planejamento e desenvolvimento - SEPLAN-RR. 
Além das comunidades às margens do rio Branco, a expedição científica percorreu e visitou comunidades nos rios Xeurini, Amajaú, Caicubí e Jauaperi, na jurisdição dos municípios de Caracaraí e Rorainópolis, ambos do estado de Roraima, conforme demonstra a Tabela 1.

Tabela 1: Comunidades visitadas, população, rio e município

\begin{tabular}{lrcc}
\hline \multicolumn{1}{c}{ Comunidade } & População & Rio & Município \\
\hline Santa Maria do Boiaçu & 1.444 & Branco & Rorainópolis \\
Santa Maria Velha & 53 & & \\
Dona Cota & 41 & & \\
Sacaí & 25 & & Caracaraí \\
Terra Preta & 450 & Xaurini & \\
Lago Grande & 193 & & \\
Canauaní & 158 & Amajaú & \\
Cachoeirinha & 151 & & \\
Caicubi & 604 & Caicubi & \\
Panacarica & 124 & Negro & \\
Remanso & 89 & & Rorainópolis \\
Floresta & 160 & & \\
Bela Vista & 30 & Jauaperi & \\
Itaquera & 154 & & \\
Samauma & 167 & & \\
Xixuaú & 122 & &
\end{tabular}

Fonte: Elaborada a partir de mapas topográficos, trabalho de campo realizado em 2019 e dados do Instituto Brasileiro de Geografia e Estatística - IBGE, 2010.

$\mathrm{Na}$ realização deste trabalho, optamos pelas conversas informais com membros das comunidades, incluindo mulheres de idades variadas, em sua maioria com a família já formada, mesmo as jovens mães. Nas áreas rurais ribeirinhas é comum formar família muito cedo. Contamos também com depoimentos gravados e filmados de mulheres e de lideranças comunitárias que, em outros momentos serão trabalhados para construção de um documentário. Em alguns momentos foi possível realizar uma roda de conversa com a comunidade e a presença das mulheres eram bem significativas. Nas rodas de conversas, a equipe apresentava seus objetivos. Na oportunidade a comunidade apresentava as suas demandas e expectativas, bem como, depositava na equipe as possibilidades de parcerias para o fortalecimento das várias ações propostas.

As experiências e vivências no Baixo Rio Branco resultaram neste texto, que tem como objetivo situar o leitor sobre alguns aspectos do modo de vida das comunidades ribeirinhas Amazônicas. Ele apresenta mais que impressões de percurso, mas reflexões que tratam do Bem-Viver das comunidades, destaca o papel das mulheres, discute a educação ambiental e a qualidade de vida das comunidades e, por fim, destaca as dificuldades para a geração de energia elétrica, mais um item fundamental para prover qualidade à vida das famílias que vivem no Baixo rio Branco.

\section{Encantarias amazônicas: do modo de vida ao Bem-Viver}

Quando utilizamos o termo "ribeirinho" não estamos somente nos referindo a quem mora às margens de um rio ou igarapé, mas a quem essencialmente mantém uma organização social diferenciada da urbana, com sua vida baseada principalmente na pesca, na pequena produção agrícola (caracteristicamente mandioca para produção de farinha, frutos como a melancia, plantada nas várzeas dos rios e plantações perenes como o cupuaçu, a pupunha e o açaí) e que pratica a coleta de produtos da mata como a castanha-do-brasil, o açaí, a bacaba e o patoá, que ocorrem naturalmente na área. Morar às margens de um rio ou igarapé não é suficiente para ser considerado ribeirinho, pois o vocábulo reúne uma diversidade de formas de viver da população amazônica.

Silva (2000) define ribeirinho como aquele que essencialmente mantém uma organização social diferenciada da urbana, com sua sobrevivência econômica baseada principalmente na pesca, coleta de determinados produtos da mata e pequena produção agrícola. Para discutir populações tradicionais ver Oliveira (1987), Porto Gonçalves (2001 e 2017), Faria, (2012), Almeida (2013 e 2019), Pimentel e Ribeiro (2016), Laschefski e Zhouri (2019). Aqui chamamos a atenção para o uso do termo "mata", ao invés de "floresta", pois a "mata" envolve o conhecimento, intimidade e as relações míticas com toda a cobertura vegetal. É um termo genérico para a floresta mas que inclui a vivência, conhecimentos e saberes. O ribeirinho não vai na "floresta" buscar açaí, mas sim, na mata. 
A Amazônia é composta por rios, florestas e elementos do imaginário de sua população, que são vivenciados perante relações de troca e, até mesmo, de certa imbricação da relação entre seres humanos e a natureza, da qual o ribeirinho constrói sua vivência. A relação entre o indivíduo e seu lugar, abrangendo tanto os componentes naturais, quanto os construídos por eles próprios, permite estabelecer um sentido de vida e de pertencimento, que passa a ser a base do viver ribeirinho.

O modo de vida ribeirinho é uma composição do modo de vida rural, em especial nos aspectos culturais e produtivos. Além da pesca, ele depende da terra e de seu cultivo. A visão de produção do ribeirinho não ultrapassa a necessidade cotidiana de alimentar a si e a sua família, ligada quase que exclusivamente, ao que produz. Essa característica de auto sustentabilidade consiste em uma descendência cultural do que era conhecido o camponês tradicional, que constituía uma sociedade econômica bastando-se a si mesma. Portanto, o ribeirinho é, também, um agricultor que tem na produção agrícola sua estratégia de sobrevivência.

O modo de ser ribeirinho está caracterizado por uma concepção de natureza diferente, por integrar em seu modo de vida os elementos essenciais disponíveis: as águas e as matas e, desses elementos, estabelecer suas estratégias de sobrevivência, seus valores éticos e estéticos, e seus sonhos. É preciso que os ribeirinhos sejam vistos com sua singularidade, sem os aspectos que os diferenciam. Essa diferença está marcada no sentir, no perceber, no olhar e no lazer. A cultura ribeirinha está caracterizada nas representações míticas do grupo, nas festas de santos, nas formas de produzir o sustento e na influência que o calendário agrícola recebe do rio.

As comunidades ribeirinhas surgem no processo de avanço da ocupação da Amazônia em parte vinculada às atividades de explorações econômicas, mas que não foram devidamente incluídas dentro das estratégias de desenvolvimento do estado. Esse processo foi estudado por Théry (1982), Oliveira (1987, 1988 e 2016), Ab'Sáber (1996), Porto Gonçalves (2001), Becker (2004), Mello-Théry (2006 e 2011) e Castro (2017), entre outros.

A título de exemplo, a formação da população ribeirinha de Rondônia, está relacionada principalmente às atividades de exploração da borracha, do primeiro e do segundo momento, final do século XIX e meados do século XX, respectivamente. São comunidades que se estabeleceram na mata, nas margens dos rios e igarapés, quando essas atividades econômicas se encerraram. As comunidades descendem dos grupos de pessoas que procuraram sobreviver a qualquer custo, sem que houvesse qualquer aparato de políticas públicas.

Essa é uma característica muito marcante na Amazônia gomífera de Roraima, Rondônia, Acre e Amazonas. As comunidades localizadas nesses estados apresentam trajetórias semelhantes na maneira de organização social e produtiva, marcada, principalmente, pela pequena agricultura familiar para sua reprodução com utilização das terras de várzea para produção de melancia, feijão, milho, macaxeira e pela extração de produtos florestais e pesca. A extração está centrada no açaí e na castanha.

Ao longo do tempo, a permanência desses seringueiros às margens dos rios, igarapés ou mesmo na mata, tomou uma nova característica em sua estratégia de sobrevivência. Tal estratégia utiliza os recursos disponíveis na mata e nas terras de várzea e praias dos rios constituindo-se o "viver ribeirinho", que não é homogêneo. Há diferenciações definidas por inúmeros aspectos, sejam históricos, culturais ou econômicos. O viver ribeirinho não está voltado apenas para a produção de mercadorias e se sustenta em trocas ou ações de solidariedade.

O viver ribeirinho cria seu espaço geográfico em sua formação, constituído de seu próprio universo social, que reconstitui sua identidade específica como grupo e a relação social com a natureza torna-se diferenciada. $\mathrm{O}$ viver ribeirinho vai caracterizar o específico sistema do universo social e permite entender os meios de subsistência do grupo. Possibilita ainda estudar a relação entre o tipo de agricultura e o ambiente, bem como "capturar" o funcionamento cotidiano da comunidade e as múltiplas relações sociais, econômicas, religiosas, políticas, ambientais, além do papel das representações simbólicas que o ribeirinho constrói em relação as águas e as matas.

Tempo e espaço são vivenciados em uma concepção que não privilegia a lógica da mercadoria. Não é certo dizer que as comunidades são organizações pré-capitalistas. Também não são organizações póscapitalismo ou mesmo que façam quaisquer enfrentamentos ou esforços de resistências ao capitalismo. As agências financiadoras, ao se afastarem da atividade de exploração da borracha, e os empresários seringalistas, ao abandonarem suas imensas áreas onde funcionavam seus seringais, deixaram tudo para trás: as estruturas físicas (casas, barracões e maquinários) e os seringueiros trabalhadores. Esse conjunto mergulhou em um adormecimento que leva décadas. E isso ocorreu outras vezes em outros lugares. 
Já os seringueiros tratam de suas vidas. Para eles, o tempo e o espaço são voltados para a vida. Eles organizam o seu tempo no que o ambiente oferece para suas atividades. Tem o tempo do plantio da mandioca, da colheita e produção de farinha. Tem o tempo da colheita do açaí, e a maior parte desse açaí ocorre naturalmente; a colheita da castanha; a coleta dos óleos da copaíba, da andiroba; o tempo do plantio do milho, da melancia e do feijão nas praias dos rios; o tempo da pesca, das piracemas, dos cardumes de sardinhas, pacus, jatuaranas, dos grandes bagres como o filhote, o dourado, a piraíba. Eles aprenderam a ouvir e distinguir os barulhos das águas pois ouvem de longe o som das jatuaranas subindo os rios e se preparam para a festa da fartura.

Em se tratando desses modos de vidas e organizações sociais, é preciso demonstrar a dinâmica de funcionamento do ambiente, a relação de sua produção extrativista e/ou agrícola em busca de compreender o ser ribeirinho, como pensa e percebe seu meio, seus temores, suas representações oníricas, míticas, simbólicas. Não é uma Amazônia fácil de se ver e também não é tarefa das mais simples expressar um modo de viver caboclo, ribeirinho. Torna-se necessário um atencioso trabalho de verificação para captar esse modo de viver. Em alguns momentos, as conclusões que elaboramos se volatizam.

Por meio da expedição, observamos que essas comunidades, ao se organizarem e definirem suas estratégias, mantêm ainda sua específica forma de se relacionar com a natureza. Tal relação tem sua singularidade porque não é de domínio, não é marcada pelas necessidades do mercado, é, sim, voltada para a vida. A relação que essas comunidades têm com a natureza é de proximidade, marcada pela necessidade de manter a especificidade de seu viver, estabelecerem a organização de seu planejamento utilizando-se de padrões como o período da colheita do açaí, o período da colheita da castanha, o plantar, colher a mandioca, produzir a farinha e a chegada dos turistas. Esse modo de vida está imbricado a esses marcadores culturais.

O modo de vida ribeirinho, oriundo das atividades extrativas da borracha, bastante ativo no período da Segunda Guerra Mundial e que vai perdendo o poder e interesse econômico a partir do final da década de 1940, mas que se acentua nas décadas seguintes, encontra, na década de 1970, o processo de colonização induzido pelo estado. Esse conjunto de ações afeta o ribeirinho, que se expressa em movimentos sociais. Entretanto, ao longo desse tempo, o modo de vida ribeirinho persiste em existir em pleno século XXI.

Em visita às comunidades do baixo Rio Branco, encontramos uma organização e modo de vida de grande similaridade com as populações ribeirinhas do rio Madeira, em Rondônia. Entre os temas apresentados a membros das comunidades estava uma questão central para compreender o modo de vida: o que era o BemViver?

O Bem-Viver é uma forma de vivenciar a relação com a natureza, de um ponto de vista que não passa pelas relações de objetificação das relações de mercado. O Bem-Viver é uma forma de manter a vida; é um conceito que nasceu entre as populações indígenas do Brasil e está também presente em populações locais tradicionais da América Latina. É um conceito que traz a premissa da relação de equilíbrio no trato dos recursos e considera a natureza uma parceira. No Bem-Viver não existe a dicotomia entre o humano e a natureza, pois o ser humano se considera também como natureza. O Bem-Viver está presente no modo de vida da maioria das comunidades indígenas da Amazônia. Ele se caracteriza pelo respeito e pela sacralidade em relação à natureza. Mas observam-se nessas comunidades drásticas mudanças.

As comunidades do Baixo rio Branco apontaram que vivenciar a condição do Bem-Viver era estar em paz, alimentar a família e pescar, trazer o pescado para a família e estar seguro naquele local. O que de fato importava era organizar a vida. Não se trata de acúmulos materiais ou de equipamentos. O modo de vida é marcado pelo viver bem em estado de tranquilidade e de equilíbrio. Esse modo de vida, e sua relação com a natureza, resgata a condição da humanidade. Trata-se da condição e maneira de encarar a vida e de estar no mundo.

Podemos encontrar formas de pensar a vida e estabelecer relações de entendimento, de convívio, que fornecem elementos para pensar conceitos que são fundamentais para a vida, como felicidade e sentir-se completo, centrado. O conceito de Bem-Viver oferece essa possibilidade de reflexão crítica ao mundo marcado pelas relações da mercadoria, no qual aquelas possibilidades parecem ser utópicas, inúteis, desnecessárias ou improváveis.

Ao encontramos o Bem-Viver em lugares diversos, nos quais vivem distintos povos com suas manifestações culturais, podemos observar que ele é uma manifestação destas organizações sociais, desses povos na Amazônia. Mas ele não se restringe a essa parte da América do Sul. O Bem-Viver está presente em comunidades andinas que vivem no Perú, assim como na Bolívia, na Colômbia e no Equador, esses três países que incluíram essa relação com a natureza na Constituição. 
Compreendemos que esse é um debate que se faz de uma forma ainda muito tensa, que tem em Alberto Acosta (2016), o autor e principal articulador dessa proposta no Equador, um de seus expoentes. Mas discutir que a natureza precisa ser vista de uma maneira diferenciada não é uma expectativa ou uma observação apenas de localidades ou de famílias envolvidas com o Bem viver, é uma necessidade premente.

Diante do que estamos vivendo tanto em uma escala nacional, como latino-americana, em que verifica-se uma tendência de intensificar as relações que o capital faz, em que se acentua a exploração, essa discussão mais do que nunca se torna importante porque precisamos nos reencontrar enquanto seres humanos. Precisamos nos reencontrar enquanto valores que a nossa existência desenvolve para a vida. Essa é também uma discussão que nos põe um desafio: colocar o Bem-Viver não como uma alternativa ou não ao capital, mas para pensar para além do capital, para pensar organizações, possibilidades e alternativas de reprodução da vida, como os ribeirinhos do baixo rio Branco nos mostraram na Amazônia.

\section{Mulheres às margens do rio Branco}

Outra meta do trabalho de campo foi saber como vivem as mulheres, qual o papel que vivenciam e desenvolvem em suas comunidades. Um dos objetivos era registrar esse cotidiano e de alguma forma ouvir mulheres para que pudessem expressar suas demandas, angústias, sonhos e esperanças, bem como, saber se o rio "comanda" de fato, suas vidas.

O espaço ribeirinho da Amazônia apresenta uma série de complexidades. Entre essas, as relações e os fatores sociais que estabelecem, muitas vezes de maneira paradoxal, delimitando espaços e constituindo relações. Ser homem e ser mulher implica em uma diferenciação de atividades a serem exercidas e de espaços a serem ocupados.

As mulheres ribeirinhas têm suas vidas marcadas pelos calendários agrícolas que são definidos pela dinâmica do rio. Durante a pesquisa de campo, percebemos que chegamos no período da colheita da mandioca para a produção de farinha. A colheita do açaí (natural pois não nos foi relatado a existência de plantio de açaí) estava se encerrando, as águas estavam no auge do período da cheia e a mandioca estava madura. Os ciclos das atividades se repetem nas diversas comunidades: colheita da castanha, colheita do açaí, colheita da mandioca, turismo da pesca e o reinício dos ciclos. Naquele momento, praticamente em todas as comunidades, o trabalho principal das famílias era a produção da farinha porque o rio estava enchendo muito rápido. Era preciso colher toda a macaxeira (também chamada de mandioca em outras partes do país), matéria prima para preparar a farinha e seus derivados.

Há uma divisão de trabalho bem marcada no processo da preparação da farinha e seus derivados. Os homens e os rapazes vão nas roças, que geralmente ficam muito longe da residência, até mesmo na outra margem do rio, buscar a macaxeira. Após esse transporte entram em ação as mulheres, crianças e pessoas idosas, que descascam toda essa mandioca para depois colocar de molho para "pubar", ou seja, deixar de molho na água por alguns dias para que a raiz encharque e se sature de água e inicie o processo de apodrecimento (Figura 2).

Outro processo que também é realizado pelas mulheres e pelas jovens é a retirada da goma, que é um dos sub-produtos da mandioca. A extração da goma, do tucupi e da massa para fazer bolos conhecidos como de "pé-de-moleque" é um processo demorado e delicado. As mulheres e as jovens são responsáveis pela limpeza da casa de farinha. O preparo dos alimentos que serão consumidos em todo o período em que ocorre a feitura da farinha, que podem variar de oito dias a um mês, também é executado pelas mulheres.

As mulheres consideram esse trabalho muito árduo porque elas não têm muito descanso nesse período da produção ribeirinha. Ele ocorre anualmente e é mais intensificado no período que o rio começa a subir. A farinha, além de ser uma das principais fontes de renda da família, é também a base da dieta alimentar dos ribeirinhos.

As mulheres ribeirinhas têm dificuldades de falar sobre o seu lazer porque, em suas palavras, executam trabalho demais, além de serem responsáveis pelos afazeres domésticos, filhos, companheiros, roça, criações domésticas, pequenos pomares e cultivo de pequenas hortas. Algumas delas ainda se arriscam a pescar nas margens dos rios e em pequenos lagos e igarapés. Outras ainda têm como responsabilidades a limpeza e ornamentação das igrejas e capelas, que são bastante expressivas nas comunidades visitadas. 


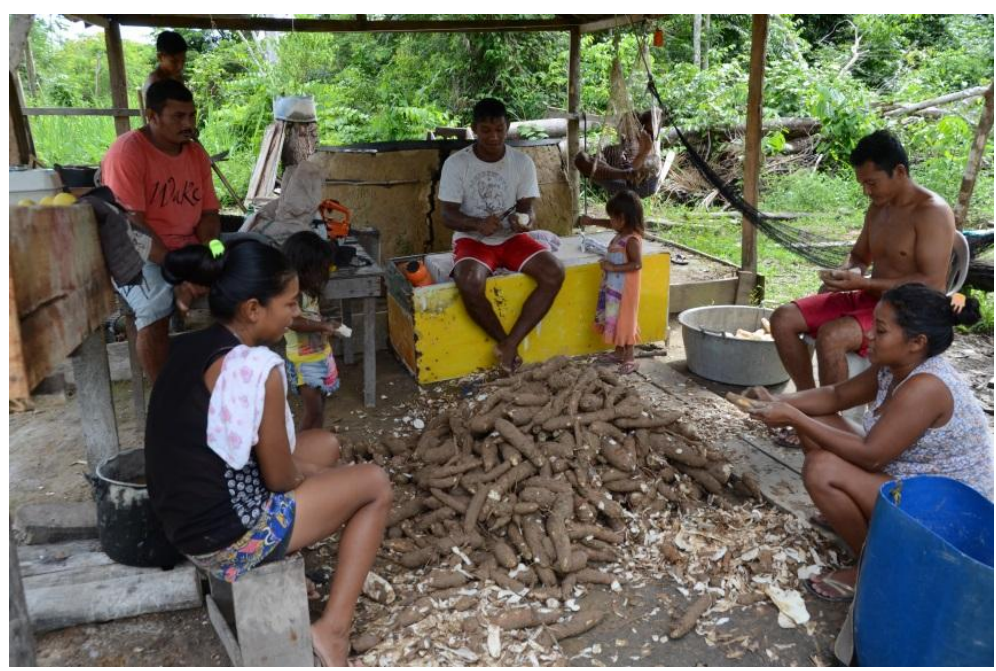

Figura 2: Panacarica, Caracaraí - RR. Toda a comunidade se envolve com a produção da farinha (homens, mulheres e crianças).

O que as mulheres relataram como lazer ainda está relacionado ao trabalho de extensão do lar, como limpar o quintal, ir às celebrações nas igrejas, assistir TV e, ao mesmo tempo, fazer alguma atividade manual, como pregar um botão em roupa, fazer um crochê e bordado, conversar na beira do rio no final de tarde, assistir um jogo de futebol, em especial dos homens (Figura 3). Entretanto, parte dessas atividades é realizado ao mesmo tempo em que cuidam dos filhos menores. Ou seja, não estão em pleno lazer.

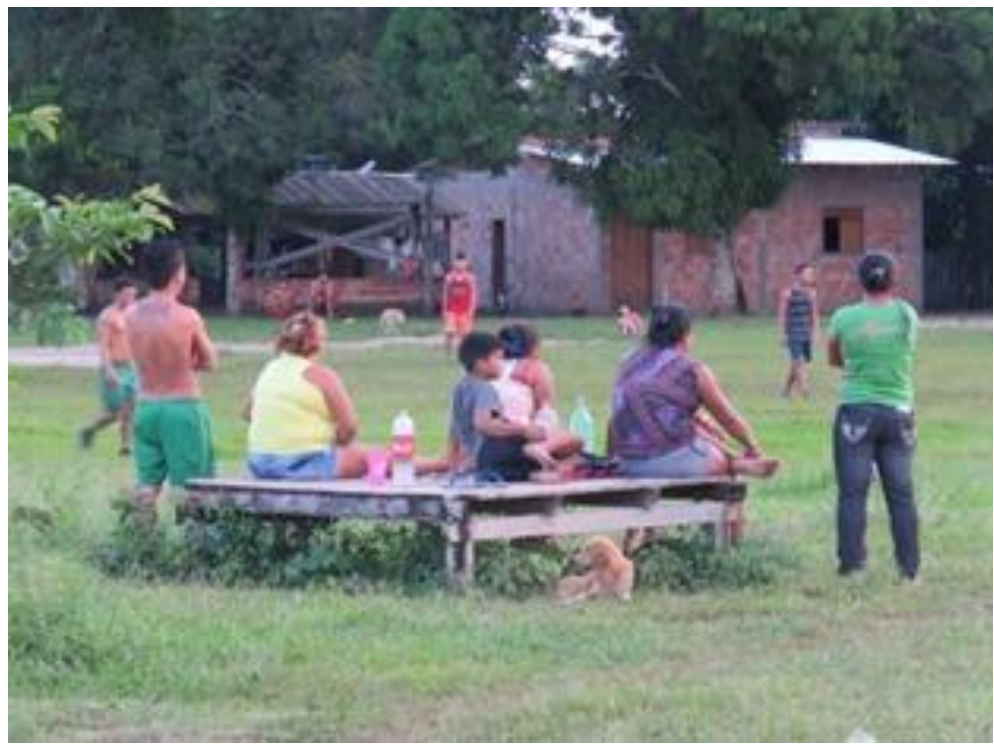

Figura 3: Caicubi, Cacacaraí - RR. Mulheres assistindo a um jogo de futebol.

Verificou-se que o "lazer" está associado a cuidar de outros, seja membros da família ou da comunidade. Mas encontrou-se também o pleno lazer em algumas mulheres ribeirinhas que jogam futebol, porque elas estão focadas apenas em jogar futebol com outras mulheres, sem se preocupar com outros afazeres.

Também cabe às mulheres a coordenação dos festejos dos Santos e das Santas padroeiros e padroeiras das comunidades. É responsabilidade das mulheres a ornamentação, os cânticos das celebrações, coordenar terços, novenas, procissão, e a alimentação durante os festejos. Já os homens são responsáveis para carregar o andor da Santa ou do Santo, pela festa, que consiste em bingos, leilões, baile, pelo futebol e tudo que é público e que de alguma forma tenha uma arrecadação financeira. Os homens são sempre os responsáveis pela tesouraria dos festejos.

Outro trabalho realizado pelas mulheres, muito presente em áreas rurais, é o da parteira. Nas comunidades ribeirinhas do Baixo rio Branco encontra-se algumas parteiras ribeirinhas, uma categoria de mulher muito atuante e respeitada, que possui prestígio e influência na comunidade. Uma das mulheres parteiras relatou a seguinte situação sobre o seu trabalho: 
Eu tenho maior prazer de atender as pessoas, não sei a soma de menino que já nasceu comigo, mas eu nunca cobrei nada por ter assistido com as mulheres. Tenho passado noites de sono e fome, porque a senhora sabe que tem gente muito pobre de não ter nada para comer, a gente passa a noite sem ter nada, quando vêm me buscar eu vou qualquer hora do dia e da noite e estou viva graças a Deus (parteira ribeirinha).

Esta é uma parteira conhecida como aquela que possui um dom ou um carisma. Geralmente as parteiras são católicas, até porque o "dom" está muito ligado às questões do sagrado, a que mais se aproxima da realidade ribeirinha. $\mathrm{O}$ dom é aquele que surge pela revelação, que pode ser pelo oráculo, por sorteio, por designo de Deus ou de outras técnicas de seleção. Como podemos verificar na fala da parteira o seu dom, surgiu "por designo de Deus":

O primeiro parto que eu fiz, morava no seringal aí não tinha como, aí meu dom dava para eu acompanhar aquela paciente, aí eu ajeitei a mulher muito bem, mas a criança nasceu laçada (cordão umbilical no pescoço) e eu deslacei" (parteira ribeirinha).

As mulheres que pariram com parteiras sempre relacionam o dom como um saber divino, pois a pessoa já nasce com esse saber, ou seja, não é um saber adquirido. Quando perguntado às mulheres sobre a principal característica de uma parteira de dom, elas disseram que são aquelas que agem com "sabedoria e paciência".

\section{Educação ambiental e qualidade de vida}

A Constituição Federal do Brasil define a Educação Ambiental como os processos por meio dos quais o indivíduo e a coletividade constroem valores sociais, conhecimentos, habilidades, atitudes e competências voltadas para a conservação do meio ambiente, bem de uso comum do povo, essencial a sadia qualidade de vida e sua sustentabilidade. Nesses termos, a Amazônia, impotente perante o controle imponente e voraz do capital, vive à margem da educação ambiental.

A Hiléia Amazônica é um mundo sem fim, cuja riqueza vegetal, animal, mineral e hídrica é impossível ser dimensionada, ainda que tenha sido muito bem analisada em diversos trabalhos de AB'SÁBER (1989, 1996, 2002 e 2010). Todavia, na Amazônia brasileira, com seus 5.000 .000 km², encontram-se inúmeras categorias que agem sem serem totalmente responsabilizados por seus atos, tais como os exploradores madeireiros, mineradores, pecuaristas, incendiários, grileiros, pescadores, atravessadores e aventureiros de toda natureza. E, por conseguinte, os povos da floresta estão à mercê da reunião dessas forças. Assim, a preservação dos bens naturais e do patrimônio cultural é quase uma utopia no Baixo rio Branco.

Estão estabelecidas na região cinco unidades de conservação: o Parque Nacional Viruá, a Reserva Ecológica do Niquiá, a Floresta Nacional Anauá, a Área de Proteção Ambiental do Baixo rio Branco e a Reserva Extrativista do Baixo rio Branco - Jauaperi. Porém, as áreas protegidas foram implantadas, mas não consolidadas. Ao que se sabe, somente uma possui sede - o Parque Nacional do Viruá, cujo diretor reside em Boa Vista, capital de Roraima.

O entorno das unidades de conservação é habitado pelos povos indígenas Yanomami e Waimiri-Atroari, ao passo que no interior e bordas das áreas protegidas vivem os ribeirinhos, cujo acesso, na maioria das vezes, somente é possível pelo ar ou pela água.

As áreas protegidas, por si só, justificam um amplo programa e ações de educação ambiental nas comunidades caboclas e indígenas, por órgãos federais, estaduais e municipais, incluindo as escolas e as secretarias de saúde. Numa abordagem mais ecológica e romântica, nesses ambientes protegidos por lei se vislumbra a natureza clímax em perfeito equilíbrio. Seria o equilíbrio da "sociobiodiversidade", definida como a sintonia harmônica entre a multiplicidade de espécies animais e vegetais com a diversidade social, de modo a preservar os bens naturais e o patrimônio étnico-cultural (SEABRA, 2011).

Por via fluvial, centenas de quilômetros de águas fluem em desacordo com a ínfima físcalização e policiamento. Neste "paraíso das águas" impera a lei dos mais fortes. É a lei da selva (SEABRA, 2019). No percurso de 10 dias, o barco usado pela expedição foi abordado apenas uma vez por uma patrulha que envolvia diversos segmentos policiais, como polícia militar e ambiental.

A educação ambiental enfatiza a qualidade de vida e a sustentabilidade. Porém, atualmente a "qualidade de vida" está associada à aquisição de bens de consumo diversos, de primeira necessidade, descartáveis e "duráveis". No Baixo rio Branco o consumo é restrito, porque salário praticamente não existe. Nesse contexto, a qualidade de vida abre uma perspectiva para pensar a equidade social no sentido da diversidade ecológica e cultural. Atitudes louváveis dos moradores, em quase todas as vilas, é o reaproveitamento de 
carcaças de eletrodomésticos e outros utensílios que servem como objetos utilitários, decorativos e brinquedos. Canoas desativadas são utilizadas no cultivo de hortaliças, numa combinação harmoniosa com as palafitas (Figura 4).

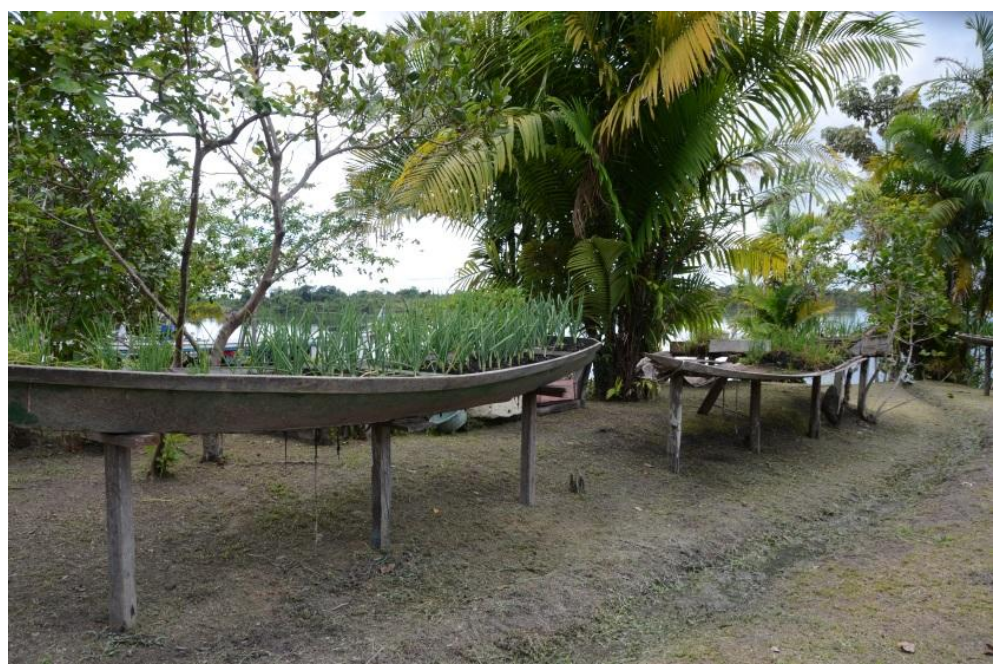

Figura 4: Lago Grande, Caracaraí, RR. Muito comum o reaproveitamento de velhas embarcações, utilizadas no cultivo de hortaliças.

A qualidade de vida não é aquilatada na balança dos níveis de renda, dos salários reais e das normas de satisfação de necessidades economicamente estabelecidas e propagadas pela mídia (LEFF, 2009). Na região, a vacância é aberta pela ausência das políticas públicas o que abre espaço para a autogestão sustentável, sobretudo em nível familiar, das populações ribeirinhas. Os rendimentos familiares básicos e suplementares são oriundos das microformas de arranjos produtivos locais, cujos insumos são colhidos na roça, no rio e na mata.

Mesmo convivendo com os períodos de seca, quando os rios se reduzem a filetes de água contornando extensos areais, ou no inverno, período em que as chuvas torrenciais provocam grandes enchentes nos vilarejos, os povos ribeirinhos permanecem inabaláveis. Para todo e qualquer desafio sempre encontram uma solução. Segundo o "seu Careca" de Santa Maria Velha, município de Rorainópolis, em depoimento coletado em campo, "aqui não tem supermercado, mas tem o peixe, tem o açaí, tem a castanha, tem a farinha, tem a caça, tem tudo que a gente precisa pra viver. Além do mais, a casa e o barco são feitos com a madeira que a floresta oferece, e de graça" (Figura 5).

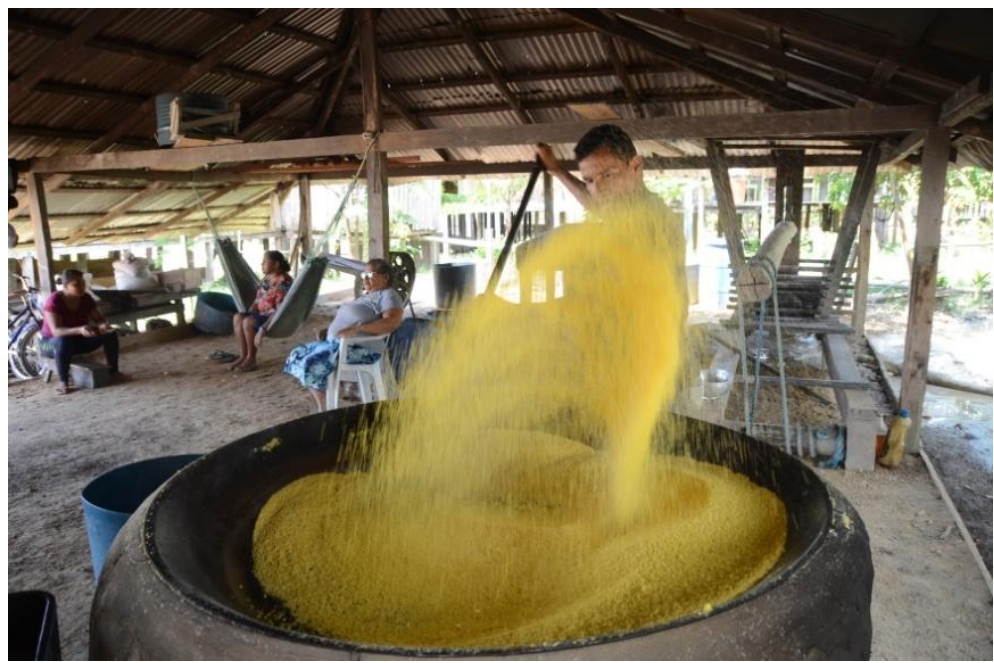

Figura 5: Sacaí, Caracaraí - RR. Casa de farinha.

Santa Maria do Boiaçu, um microcentro regional, com 700 moradores, onde falta quase tudo, é a mais bem servida de equipamentos e serviços. O porto de Santa Maria do Boiaçu não tem a menor infraestrutura para atracamento das embarcações. Os barcos estacionam amarrados uns aos outros ou nas toras flutuantes para este fim. No lugar do píer uma grande voçoroca ameaça engolir a rampa de acesso ao povoado. 
Dois médicos "sem fronteiras", um peruano e outro cubano, se revezam a cada quinze dias, para receitar remédios para pressão arterial, diabetes, soro antiofídico, e acompanhar os partos. Ginecologista e obstetra nem pensar. O pré-natal e os partos das ribeirinhas estão aos cuidados das parteiras no restante das comunidades. No logradouro principal, situado entre o hospital e a escola municipal, uma pilha de postes parcialmente cobertos pelo matagal serve como esconderijo das cobras e assentos onde os residentes captam os tênues sinais da internet livre. Como as serpentes rastejam com desenvoltura pelas ruas, as lanternas são equipamentos indispensáveis aos moradores. Sem falar nas onças, que, de quando em quando, devoram os cachorros mais atrevidos (SEABRA, 2019).

Nessa pequena localidade e nos povoados menores das cercanias verifica-se a presença de Yanomamis. A migração dos indígenas para os povoados e sítios do Baixo rio Branco é decorrência dos cortes nos recursos federais na Fundação Nacional do Índio - FUNAI e da pressão de milhares de garimpeiros no território indígena, sobretudo nas regiões do alto e baixo rio Catrimani. Aproveitando a correnteza das enchentes de abril a agosto, indígenas descem remando em frágeis canoas, durante dias, até encontrar um porto seguro. São famílias formadas de adultos e crianças que se instalam nas casas de farinha, galpões, sítios e acampamentos improvisados na floresta próxima aos povoados (Figura 6).

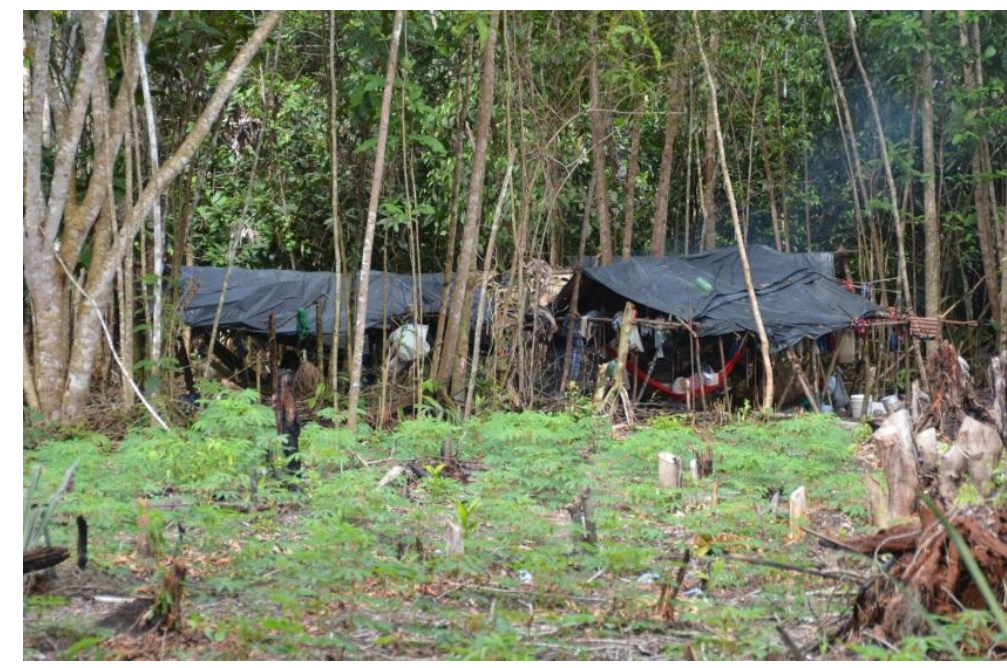

Figura 6: Santa Maria do Boiaçu, Rorainópolis - RR. Acampamento de Yanomamis.

Os indígenas envolvem-se com a limpeza dos roçados, dos sítios, dos quintais e a derrubada e queima da mata para dar lugar às pastagens. Poucos falam português.

A comunidade de Xixuaú, com 60 habitantes, entre crianças jovens, adultos e idosos é conhecida na região por desenvolver o turismo ecológico e a educação ambiental. Uma parcela da população está vinculada à Cooperativa Agroextrativista do Xixuaú - Coopxixuaú. Outros moradores estão atrelados a um projeto turístico da Associação Amazônia. Na visita, constatou-se que a comunidade está cindida entre os que apoiam essas atividades e os que preferem se articular junto a empresários de origem de fora do país, que inseriram um turismo que atrai gente de diversos países, a custos elevados para os brasileiros. Diferente de outras localidades, nessa comunidade se pratica o turismo de observação, com destaque para o mergulho nas águas cristalinas dos rios e igarapés, enquanto em outras a pesca esportiva é comum entre os turistas.

\section{Desafios para o acesso à energia elétrica}

A discussão sobre o abastecimento de energia elétrica nas comunidades ribeirinhas torna-se relevante, por ser a Amazônia, na atualidade, a maior receptora de grandes projetos hidrelétricos e, ao mesmo tempo, compor grande parte dos sistemas isolados de energia (CAVALCANTE, 2012). Os sistemas elétricos de serviço público de distribuição de energia elétrica são aqueles que não estão eletricamente conectados ao Sistema Interligado Nacional - SIN, por razões técnicas ou econômicas, regulamentado pelo Decreto $\mathrm{n}^{\circ}$ 7.246/2010 e pela Portaria MME no 67/2018. No Brasil existem aproximadamente 270 sistemas isolados. Boa Vista, em Roraima, contribui com a maior parte, com uma demanda máxima anual da ordem de 200 MW (EPE, 2019). Roraima é a única unidade da federação que ainda não está conectada ao Sistema Elétrico Nacional - SIN. A atenção nesta seção é dada ao abastecimento de energia no Baixo rio Branco, trecho do centro ao sul do Estado Roraimense, percorrido pela expedição científica. 
O rio Branco é formado a partir da confluência dos rios Tacutu e Uraricoera, sendo considerado o principal curso d'água que corta Roraima até sua foz, no rio Negro, na divisa com o Amazonas. O deslocamento é fácil no período chuvoso, no trecho que compreende o município de Caracaraí até o rio Negro. No Médio e Alto rio Branco a navegação é dificultada pelas corredeiras.

$\mathrm{O}$ acesso às comunidades existentes na região do Baixo rio Branco é via fluvial, porém, não há linhas regulares de transporte fluvial de passageiros. O deslocamento de pessoas ocorre por meio de pequenas embarcações (voadeira ou pequenos barcos impulsionados por rabetas). A região é desprovida de malha viária e linhas de voos regulares. Acesso aéreo pode ocorrer apenas na localidade de Santa Maria do Boiaçu, município de Rorainópolis, onde existe uma pista de pouso para aeronaves de pequeno porte, sendo que a maior frequência é de voos fretados.

O sistema de abastecimento de energia das comunidades visitadas é composto, basicamente, por unidades de geração térmicas, a cargo da Roraima Energia. O tempo de geração de energia está ligado à disponibilidade de combustível destinado a cada comunidade, com funcionamento de, em média, de $12 \mathrm{~h}$ (doze horas) por dia. A exceção é Santa Maria do Boiaçu, que possui geração de energia por 24h (vinte e quatro horas). Isso permite a esta comunidade ter acesso a melhores estruturas para atendimento em saúde e educação em relação às demais comunidades encontradas neste trecho do rio Branco. As demais comunidades têm que se dirigir até Santa Maria do Boiaçu para ter acesso a serviços de saúde de maior complexidade. Casos mais graves são encaminhados à Boa Vista, por avião.

Verificou-se um temor na comunidade porque a empresa que opera no fornecimento de energia aponta a possibilidade de instalar relógios medidores de energia nas residências. Atualmente elas pagam uma tarifa fixa. Caso ocorra essa mudança os valores pagos podem ser bem mais elevados.

A energia é um elemento importante para a organização das comunidades ribeirinhas. A disponibilidade de energia elétrica possibilita o armazenamento de produtos essenciais a estas populações, como é o caso do peixe e açaí.

Na maior parte das residências encontramos acesso à televisão por meio de sinal recebido de antenas parabólicas (Figura 7). Além disso, o freezer é muito utilizado para armazenamento de polpas de frutas. O acesso a internet é mais recente e funciona via satélite, com pontos de acesso sem fio instalados em escolas em parte das comunidades.

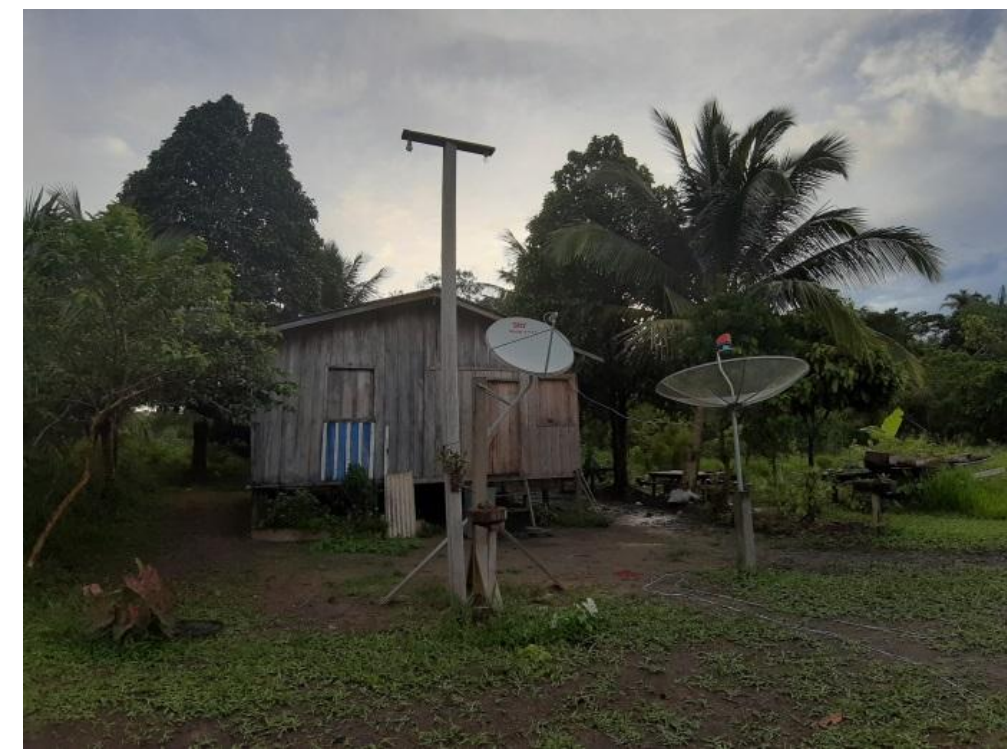

Figura 7: Xixuaú, Rorainópolis - RR. Casas com sistema para captar sinal de TV.

A rotina diária das comunidades é composta em parte pelas atividades de coleta de produtos da floresta, roça e pesca, na qual a energia elétrica contribui positivamente. No geral, a maioria dos produtos gerados pelas famílias é para o seu consumo e a prática do escambo ainda é utilizado como parte de subsistência. Por isso existe pouca circulação de dinheiro em espécie. A exceção ocorre com os que são funcionários públicos (professor e agente de saúde, por exemplo), que se deslocam para a sede do município para receber o salário, ou aqueles que recebem algum benefício (aposentadoria ou bolsa família). Um eventual aumento na tarifa, atualmente entre $\mathrm{R} \$ 30,00$ a 50,00, vai aumentar a dificuldade de muitas famílias para manter o acesso à energia. 
As comunidades recebem combustível mensalmente, o que exige um racionamento para gerar energia para o mês inteiro. No entanto, no período de seca, quando a navegação fica comprometida, ou quando o motor gerador apresenta problemas e requer manutenção ou reparos, as comunidades ficam sem energia. É o caso identificado nas comunidades de Samaúma e Xixuaú, no rio Jauaperi, nas quais os moradores relataram que estavam com mais de 30 dias sem o provimento da energia elétrica.

Na comunidade Cachoeirinha, às margens do rio Amajaú, para garantir o funcionamento de energia por 18h/dia, segundo relato do técnico que opera o motor gerador, são consumidos cerca de 180 litros de diesel por dia, o que atende cerca de 86 residências. A logística para manter os geradores em funcionamento é uma tarefa difícil e dispendiosa. Somam-se ainda os problemas ambientais relacionados ao transporte, armazenamento e exposição do óleo, que indicam vazamento nos recipientes de acomodações e ausência de isolamento da área onde fica o diesel, que é um combustível tóxico (figura 8). O diesel emite gases monóxido de carbono, dióxido de carbono e dióxido de enxofre que podem causar problemas de saúde, interferência na fauna e flora e poluição na área, principalmente quando o material é percolado com as chuvas.

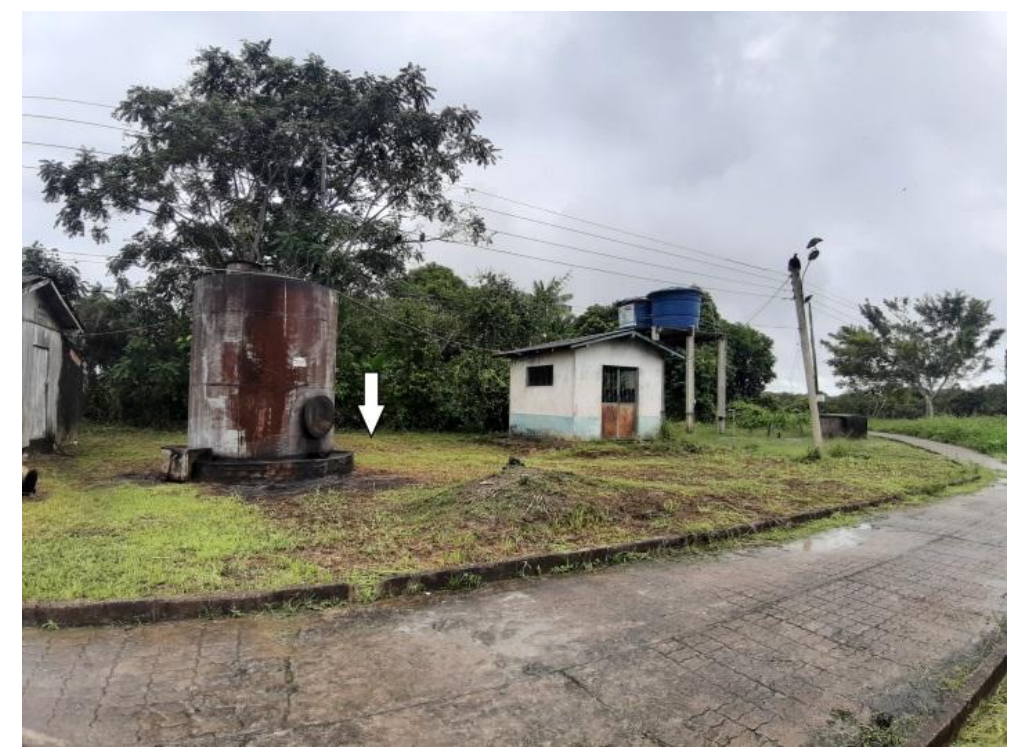

Figura 8: Caicubi e Caichoeirinha - Caracaraí - RR. Armazenamento do motor gerador de energia e de óleo diesel, respectivamente.

A eletrificação é um vetor de desenvolvimento e de inclusão social na Amazônia, como afirma Andrade (2010). A geração de energia com motor a diesel é a mais utilizada para o abastecimento de sistemas isolados, sobretudo em Roraima. No Baixo rio Branco, devido as características geográficas de baixa densidade demográfica e distância das sedes municipais, é muito caro levar linhas de transmissão de energia para interligar-se ao SIN. Por isso, atualmente essa região é dependente ao uso de diesel para gerar energia. Deste modo, considerando o alto custo de manutenção dessa fonte de energia, as dificuldades de acesso para o abastecimento de combustível e os problemas ambientais decorrentes, é preciso buscar outras alternativas de geração de energia.

O uso de painéis fotovoltaicos para aproveitar a insolação é uma alternativa às comunidades, proporcionando maior autonomia às populações ribeirinhas na Amazônia, sobretudo, com os serviços ecossistêmicos e ambientais. Os Serviços ecossistêmicos são aqui compreendidos como processos gerados pela própria natureza por meio dos ecossistemas, com a finalidade de sustentar a vida na Terra, ou seja, são responsáveis pela manutenção da biodiversidade e demais características do sistema Terra, como as condições climáticas atuais. Já os serviços ambientais são aqueles que são utilizados pelas diversas formas de organização social, a partir dos serviços ecossistêmicos, como a água) prestados por elas na conservação dos sistemas terrestres e atmosféricos.

Os sítios ocupados pelas comunidades têm, em geral, muita insolação, o que pode garantir o fornecimento de energia elétrica. Nessa situação, o emprego de óleo diesel seria apenas complementar em dias de baixa insolação ou para o período noturno. Acesso à energia elétrica de fonte solar, aliado a escolas e atendimento à saúde, contribuiria significativamente para melhorar a qualidade de vida dessa população. A ausência desses itens básicos leva ao abandono de comunidades, podendo chegar ao esvaziamento total, como é o caso da comunidade de São Jorge. 
Investir na qualidade de vida dessas populações é atuar na permanência de quem não quer "abrir mão" do seu lugar e evitar que venham ocupar áreas periféricas das grandes e médias cidades, desencadeando outros problemas sociais.

\section{Considerações finais}

No período das observações foi possível identificar uma rica pauta de pesquisa, que pode envolver diversos campos do conhecimento, como as políticas públicas, o saneamento básico e a educação, seja ela formal ou não. Mas também foram identificados graves problemas.

Nas escolas, ou nas pequenas construções em madeira nas comunidades menores, uma mesma sala de aula acomoda três ou quatro turmas, cujos alunos são de diferentes níveis e idade. A água servida aos alunos (e muitas vezes a usada pela comunidade) é retirada do rio, quase sempre sem qualquer tratamento. Os professores que habitam os povoados são exceção, pois residem a poucos passos da escola, onde ensinam aos próprios filhos, sobrinhos e a prole dos vizinhos. A maior parte, como os médicos, vivem em centros urbanos maiores e se deslocam periodicamente até as comunidades.

Quando o olhar foca nas mulheres, o reconhecimento do papel social das parteiras permanece nas comunidades. Além disso, elas desempenham múltiplas ações, que envolvem o cuidar da moradia e da roça.

As discrepâncias entre as comunidades são notórias. Mesmo em Santa Maria do Boiaçu, a "metrópole" regional, onde existe uma melhor infraestrutura, ela é muito menor que nos bairros da capital roraimense, por exemplo. E em diversas comunidades ela simplesmente não existe.

Destaque-se ainda a presença dos povos indígenas entre as comunidades, que acabam empregados para tarefas simples e têm seu modo de vida ignorado.

Ainda que as condições em infraestrutura de saúde e educação das comunidades ribeirinhas do Baixo rio Branco sejam limitadas, a fartura de alimentos extraídos da floresta, como é o caso do açaí, o peixe retirado dos rios, somando-se aos pequenos roçados que produzem a goma e farinha derivado da mandioca, parece suprir as condições básicas à reprodução do modo de vida. No entanto, o acesso a energia de qualidade é um elemento essencial para o suprimento de outras demandas, a qual contribui, sobremaneira, na melhoria de suas condições de vida e no uso racional dos recursos naturais.

O suprimento de energia por meio de painéis solares constitui uma das alternativas energéticas para o atendimento das comunidades isoladas, reduzindo a dependência do óleo a diesel e diminuição dos impactos ao ambiente causado por esse derivado de petróleo. Sendo esta, também, uma contrapartida aos serviços ambientais prestados por essas comunidades.

Essas comunidades possuem um modo de vida tradicional, utilizam a pesca, extrativismo vegetal e pequenas plantações de subsistência, criando uma dinâmica e modo de vida regido pelo tempo da natureza, sobretudo, pela dinâmica dos rios, adequando-se ao que a natureza tem a oferecer. A coleta de castanha e, sobretudo, o cultivo da roça de mandioca, encontra-se presente em todas as comunidades, já que a farinha, a goma e a farinha de tapioca constituem alguns dos principais produtos da região. Nota-se ainda o cultivo de hortaliças e frutíferas, com destaque para a banana, cupuaçu e melancia.

Em todas as comunidades visitadas o nível de satisfação com o lugar onde vivem é alto. No Baixo rio Branco, idosos, adultos, jovens e crianças são alegres e vibrantes como a dinâmica da floresta e do rio. Riem e se divertem com a própria sorte, incerta e oscilante como as águas dos rios. Por conseguinte, noventa por cento dos entrevistados preferem viver onde estão, ao invés de migrar para outra localidade ou cidade, pois receiam não encontrar trabalho, tampouco lugar para morar, ou o que comer.

\section{Referências}

AB'SÁBER, A. N. Amazônia: do discurso à práxis. São Paulo: Edusp, 1996.

AB’SÁBER, A. N.. Zoneamento fisiográfico e ecológico do espaço total da Amazônia Brasileira. Estudos avançados, São Paulo, v. 24, n. 68, p. 15-24, 2010. Disponível em <http://www.scielo.br/scielo.php?script=sci_arttext\&pid=S0103-40142010000100004\&lng=en\&nrm=iso>.

AB'SÁBER, A. N. Bases para o estudo dos ecossistemas da Amazônia brasileira. Estudos Avançados, 16(45), 7-30, 2002. Disponível em <https://dx.doi.org/10.1590/S0103-40142002000200002>. 
AB'SÁBER, A. N. Zoneamento ecológico e econômico da Amazônia: questões de escala e método. Estudos avançados. São Paulo, v. 3, n. 5, p. 4-20, 1989. Disponível em <http://www.scielo.br/scielo.php?script=sci_arttext\&pid=S0103-40141989000100002\&lng=en\&nrm=iso>.

ACOSTA. A. O bem viver: uma oportunidade para imaginar outros mundos; tradução de Tadeu Breda.São Paulo : Autonomia Literária, Elefante, 2016.

ALMEIDA, A. W. B. de. Antropologia da Amazônia: dissonância e desafios à institucionalização. Manaus: PNCSA / UEA, 2019.

ALMEIDA, A. W. B. de; FARIAS JUNIOR, E. A. (Org.). Povos e comunidades tradicionais: nova cartografia social. Manaus: UEA Edições, 2013.

ANDRADE, C. S. Energia elétrica e as populações tradicionais do Estado do Amazonas: aprendizados a partir da experiência na Comunidade do Roque na Reserva Extrativista do Médio Juruá. Rio de Janeiro, Tese (Doutorado em Planejamento Energético) UFRJ/COPPE, 2010. 264 p.

BATISTA, S. P. M.; RIBEIRO, W. C. Mecanismos da produção de injustiça socioambiental em ambientes urbanos. In: SCHOR, T. (Org.). Dinâmica urbana na Amazônia brasileira. Manaus: Editora Valer, 2014.

BECKER, B. A urbe amazônida: a floresta e a cidade. Rio de Janeiro : Garamond, 2013.

BECKER, B. Amazônia: geopolítica na virada do III milênio. Rio de Janeiro: Editora Garamond, 2004.

CASTRO, E. M. R.. Territórios em transformação na Amazônia. 1. ed. Belém: Editora do NAEA/UFPA, 2017.

CAVAlCANTE, M. M. de A. Hidrelétricas do rio Madeira-RO: território, tecnificação e meio ambiente. Tese (doutorado) - Universidade Federal do Paraná - UFPR. Programa de Pós-Graduação em Geografia PPGG. - Curitiba, 2012.

EGLER, C. Dinâmica espacial e rede urbana na Amazônia. Boletim Regional. Brasilia, Ministério da Integração Nacional, p. 6-13, mai/ago, 2006.

Empresa de Pesquisa Energética - EPE. Planejamento do atendimento aos Sistemas Isolados horizonte 2023 - Ciclo 2018. N. EPE-DEE-DEA-NT-005/2018-r1, 2019. Disponivél em http://www.epe.gov.br Acesso em 02 de julho de 2019.

FARIA, I. F.. Ecoturismo Indígena: território, sustentabilidade, multiculturalismo. 01. ed. Sao Paulo: Annablume, 2012.

LASCHEFSKI, K.; ZHOURI, A. . Povos indígenas, comunidades tradicionais e meio ambiente a 'questão territorial' e o novo desenvolvimentismo no Brasil. Revista Terra Livre, v. 1, p. 241-285-285, 2019. Disponível em <http://www.agb.org.br/publicacoes/index.php/terralivre/article/view/1552>.

LEFF, E. Saber ambiental: sustentabilidade, racionalidade, complexidade, poder. Rio de Janeiro: Editora Vozes, 2009.

MELLO-THÉRY, N. A. de. Território e gestão ambiental na Amazônia: terras públicas e os dilemas do Estado. São Paulo : FAPESP/Annablume, 2011.

MELLO-THÉRY, N. A. de. Políticas territoriais na Amazônia. São Paulo : Annablume Editora, 2006.

NUNES, D. A.; TRINDADE JR., S-C. C.; TRINDADE, G. O. . Cidades médias na Amazônia brasileira: da centralidade econômica à centralidade política de Marabá e Santarém (Estado do Pará). Confins (Paris), v. 29, p. 1-21, 2016. Disponível em <https://journals.openedition.org/confins/11376>. 
OLIVEIRA, A. U. de. A fronteira amazônica matogrossense: grilagem, corrupção e violência. São Paulo: Iandé $\quad$ Editorial, $2016 . \quad$ Disponível <http://agraria.fflch.usp.br/sites/agraria.fflch.usp.br/files/A\%20FRONTEIRA\%20AMAZ\%C3\%94NICA\%2 0MATO\%20GROSSENSE.pdf>.

OLIVEIRA, A. U. de. Integrar para não entregar: políticas públicas e Amazônia. Campinas-SP, Papirus, 1988.

OLIVEIRA, A. U. de. Amazônia: monopólio, expropriação e conflitos. Campinas-SP, Papirus, 1987.

PIMENTEL, M. A. S.; RIBEIRO, W. C. Populações tradicionais e conflitos em áreas protegidas. GEOUSP: Espaço e Tempo, São Paulo, v. 20, n. 2, p. 224-237, aug. 2016. ISSN 2179-0892. Disponível em: <http://www.revistas.usp.br/geousp/article/view/122692>.

PORTO-GONÇALVES, C. W. Amazônia: encruzilhada civilizatória, tensões territoriais em curso. Rio de Janeiro: Consequência, 2017.

PORTO-GONÇALVES, C. W. Amazônia, Amazônias. São Paulo, Contexto, 2001.

SEABRA, G. Baixo rio Branco, Roraima: o Brasil dos esquecidos. Brasília: NOTIBRÁS, 2019.

SEABRA, G. Educação Ambiental: caminhos para a conservação da sociobiodiversidade. In SEABRA, G. (Org.) Educação Ambiental no mundo globalizado: uma ecologia de riscos, desafios e resistência. João Pessoa: Editora Universitária da UFPB, 2011, p. 17-26.

SCHOR, T.; SANTANA, P. V. (Org.). Dinâmica urbana na Amazônia brasileira. vol.2. 1. ed. Manus: VALER, 2015.

SILVA, J. da C. O rio, a comunidade e o viver. Tese de Doutorado. Departamento de Geografia Universidade de São Paulo. São Paulo: USP, 2000.

THÉRY, H. Conquista, controle exploração da Amazonia: interpretação geográfica de quatro séculos de historia. Revista Geográfica do Instituto de Pesquisa de Geografia e História (OEA), México, v. 93, p. 79-81, 1982.

TRINDADE JR., S-C. C.; MADEIRA, W. V. . Polos, eixos e zonas: cidades e ordenamento territorial na Amazônia. PRACS: Revista Eletrônica de Humanidades do Curso de Ciências Sociais da UNIFAP, v. 9 , p. 37-54, 2016.

TRINDADE JR, S. C. da, TAVARES, M. G. da C. (Org.). Cidades ribeirinhas na Amazônia: mudanças e permanências. Belém, Ed.UFPA, 2008.

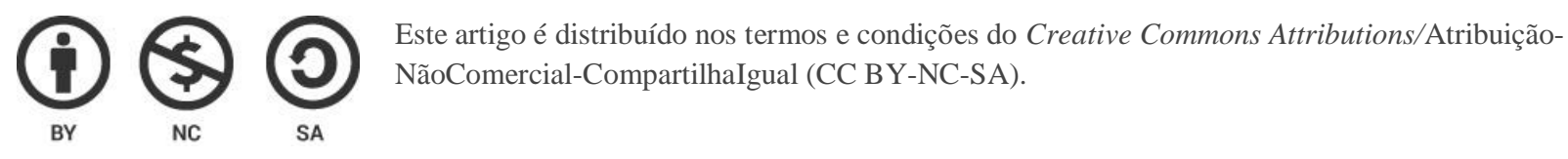

